\title{
广东深圳地区侏罗纪植物化石的发现及意义
}

\author{
王永栋 ${ }^{(12)^{*}}$ ，吴向午 ${ }^{(1)}$, 杨小菊 ${ }^{(1)}$, 段维 ${ }^{3}$ ，李丽琴 14 \\ (1) 中国科学院南京地质古生物研究所, 南京 210008 ; \\ (2) 中国科学院资源地层学与古地理学重点实验室, 南京 210008; \\ (3) 深圳中生代文化传播有限公司, 深圳 518081; \\ (4) 中国科学院大学, 北京 100049 \\ * 联系人, E-mail: ydwang @ nigpas.ac.cn
}

2013-09-16 收稿, 2014-01-02 接受, 2014-06-03 网络版发表

国家重点基础研究发展计划(2012CB822003)、中国科学院知识创新重要方向性项目(KZCX2-YW-154)、国家自然科学基金(41272010, 40972008)、中国科学院科技创新交叉与合作团队项目和国际地球科学计划(IGCP632)资助

\begin{abstract}
摘要 对海陆相三叠-侏罗纪之交重大地质生物事件的探究无不依赖于对地层格架和动植物化石 多样性的深入研究. 我国广东地区广泛发育的海陆交互相三叠-侏罗纪沉积是华南早中生代重要 的含煤地层. 但是长期以来，对于本区早侏罗世含海相动物化石的金鸡组一直没有植物化石的公 开研究记录, 制约了对该地区侏罗纪植物化石系统学和多样性的了解与认识. 本文报道近年来在 深圳大鹏半岛南澳地区金鸡组发现的一批重要植物化石标本, 初步查明了其分类学属性、保存状 况和多样性特征。该植物群以形态保存密集、羽叶和茎干连生、本内苏铁叶化石与生殖器官化石 Williamsoniella 同时保存等为特征, 代表了一个以本内苏铁植物耳羽叶(Otozamites)为主导的早侏 罗世植物群落. 这批植物化石不仅代表深圳地史时期植物群的首次发现, 也是广东和珠江三角洲 (岭南)早侏罗世植物化石的首次报道. 对这些植物化石材料的深入研究, 将有助于广东早中生代 含煤地层的对比, 加深对华南三叠一侏罗纪转换时期植物化石多样性演变的认识, 为深入探究该地 区古生态、古气候和古地理环境的变迁提供陆生植物学证据.
\end{abstract}

关键词

早侏罗世 植物化石

金鸡组

广东深圳
我国广东地区广泛发育一套海陆交互相的三叠侏罗纪沉积地层, 是华南早中生代重要的含煤地层 之一 ${ }^{[1]}$. 其中, 上三叠统小坪组为含煤碎屑岩沉积, 主要分布于粤中、粤西以及粤北和粤东地区; 侏罗系 主要分布于粤东和粤中地区, 其中下侏罗统以海陆 交互相地层为主, 自下而上由金鸡组和桥源组两个 地层单元构成. 中侏罗统则以湖相或山间盆地相为 主的沉积碎屑岩构成, 而上侏罗统则为陆相中酸性 火山岩建造 ${ }^{[1]}$. 广东晚三叠世小坪组植物化石研究历 史悠久, 并对其植物多样性面貌有了较为系统性的 了解 ${ }^{[2 \sim 4]}$, 但是长期以来, 该地区早侏罗世一直没有 植物化石的公开研究记录, 无疑对深人探究广东地
区三叠-侏罗系之交的植物多样性演变造成了制约.

广东地区早侏罗世金鸡组分布广泛, 沉积连续, 为浅海相碎屑沉积，与下伏地层上三叠统为整合接 触, 且富含海相和非海相古生物化石, 尤其以头足类 和双壳类为代表且具有良好的研究基础 ${ }^{[1,5 ~ 13]}$, 是研 究华南中生代含煤地层和三叠-侏罗系界线最有潜力 的地区之一 ${ }^{[14]}$. 由于沉积古地理的原因, 广东地区 金鸡组植物化石的分布较为局限，在该组的标准命 名地点一一开平县金鸡剖面, 除了含有丰富的属于 赫唐阶-辛纽缪尔阶的双壳类和菊石外 ${ }^{[1,10]}$, 植物化 石未见有正式报道, 仅列有零星植物化石名单 ${ }^{[14,15]}$. 另外，尽管在阳春、曲江、惠东、惠阳和揭西等地个 Chin Sci Bull, 2014, 59, doi: 10.1007/s11434-014-0449-5 
别剖面上, 曾经有采获植物化石碎片或茎干碎屑的 个别记录 ${ }^{[1,14]}$, 但没有化石图影和具体描述, 所以无 从了解植物群的概貌. 由此可见, 由于化石记录的缺 乏, 长期以来对广东地区早侏罗世植物化石系统学 和多样性的了解知之甚少.

近年来, 本文作者之一(段维)在深圳大鹏半岛地 区先后发现和采获了一批植物化石标本, 之后作者 多次前往化石产地实地考察, 确认该批化石的产出 层位为下侏罗统金鸡组, 并初步查明了该植物群的 分类学属性、保存状况和多样性特征, 在此基础上进 一步揭示该植物群与我国华南相当时期植物群的关 系及其重要意义. 本文仅对这些植物化石概况作简 要报道, 对其系统学和古植物学的细致研究结果将 随后展开并另文发表. 这批早侏罗世植物化石, 不仅 代表深圳地史时期植物群的首次发现, 填补了深圳 中生代植物化石的空白; 而且也是广东和珠江三角 洲(岭南)地区早侏罗世植物化石的首次报道. 对这些 植物化石材料的深人研究, 将有助于广东早中生代 含煤地层的对比, 加深对华南地区三叠-侏罗纪转换 时期植物化石多样性演变的认识, 还对于探究该地 区古生态、古气候和古地理环境的演变提供陆生植物 学证据.

\section{1 地质背景和地层简介}

本文报道的这批植物化石产自深圳东南部约 $60 \mathrm{~km}$
的龙岗区大鹏半岛中部，剖面地点位于南澳镇水头 沙村 $\left(22^{\circ} 34^{\prime} 42^{\prime \prime} \mathrm{N}, 114^{\circ} 27^{\prime} 60^{\prime \prime} \mathrm{E}\right)$, 西邻大鹏湾并与香 港坪洲岛隔海相望(图 1), 属深圳大鹏半岛国家地质 公园园区所辖.

大鹏半岛地区在地质构造上位于华南加里东褶 皱系的奥东隆起区, 经历了早古生代地壳活动阶段、 晚古生代和早中生代地壳稳定阶段, 晚三叠世之后 地壳处于大陆活动带并再次进人相对活动阶段, 并 以中生代火山岩系和花岗岩系的大面积分布为特征. 该地区出露的地层为中-上泥盆统和下石炭统, 侏罗 系自下而上依次发育下侏罗统金鸡组和桥源组, 中 侏罗统漳平组以及上侏罗统高基坪群 ${ }^{[16]}$.

区内的金鸡组主要出露于南澳水头沙和邻区葵 涌新塘-坪头岭地区. 水头沙剖面位于英管岭山麓, 系一套海陆交互相滨海-浅海相砂岩和泥质岩沉积, 总厚度大于 $600 \mathrm{~m}$, 最初由黄芝惠 ${ }^{[12]}$ 实测, 之后《深 圳地质》编写组 ${ }^{[16]}$ 又进行了重新测制. 该剖面底部为 花岗岩侵人体, 顶部未完整出露, 自下而上可以分成 10 余个分层(图 2). 金鸡组岩性主要由底部含砾石英 砂岩、下部细粒石英砂岩、砂质板岩以及中上部为厚 层状石英砂岩夹炭质粉砂质斑点板岩构成. 植物化 石产于该组中部深灰色和灰黑色薄层状含炭质粉砂 质斑点状板岩中(图 2).

在该剖面金鸡组上部层位中, 曾采获较多的双 壳类和菊石化石. 其中, 双壳类有 6 属 11 种, 主要包

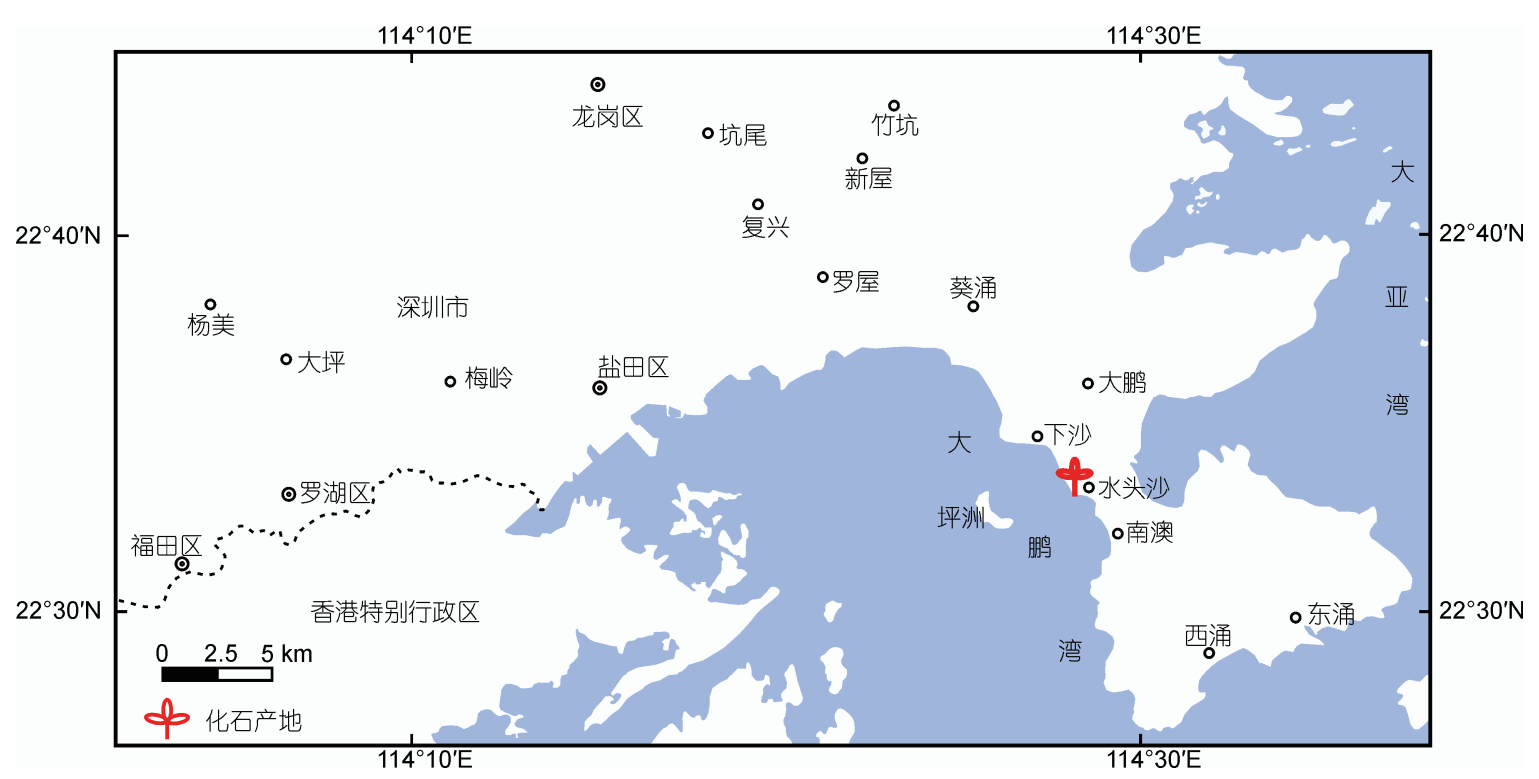

图 1 深圳南澳地区早侏罗世植物化石产地位置示意图 


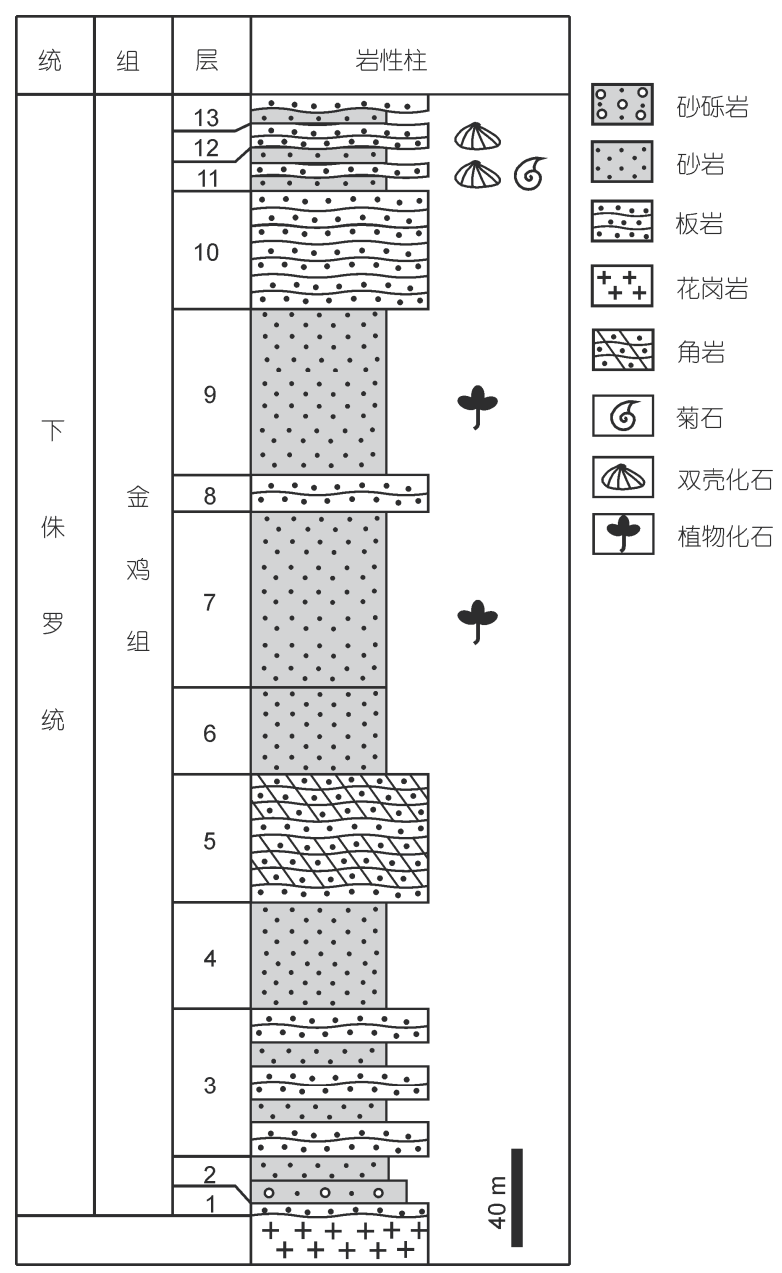

图 2 深圳南澳地区下侏罗统金鸡组地层剖面及化石层位

括 Astarte, Luciniol, Mesomilthra, Pseudotrapezium, Protocardia 以及 Homomya 等, 共生的菊石则以 Hongkongites hongkongensis Grabau 为代表 ${ }^{[12]}$. 根据 这些菊石-双壳类化石组合, 植物化石所在的金鸡组 地质时代被认为属于早侏罗世早期赫唐阶-辛纽缪尔 期(Hettangian-Sineurmurian) ${ }^{[12]}$.

本文记述的植物化石照片除了部分摄自剖面露 头外, 均保存于深圳中生代文化传播有限公司展藏标 本馆.

\section{2 植物化石概况及其多样性}

深圳南澳水头沙地区的早侏罗世植物化石均保 存为印痕标本. 化石标本为灰白色或白色印痕, 与深 灰色或灰黑色基岩反差明显. 化石形态和叶脉轮廊 清晰, 尤其是羽叶和羽轴保存较好. 除了营养器官外, 还发现有部分本内苏铁类的生殖器官化石. 在化石
产地, 可见大量密集保存在一起的本内苏铁类叶片, 且有羽叶与茎干相连生, 羽叶顶部、羽轴基部以及化 石茎干和叶片密集混杂堆积在一起保存, 且较大型 的苏铁类羽片、蒝类羽叶以及小型松柏类枝条同层保 存, 没有定向性(图 3(e)), 由此推测该化石点的植物 在埋藏前搬运的距离不会太远，接近于原位埋藏.

根据采集的标本和野外剖面观察，南澳水头沙 产地的植物化石数量十分丰富. 经局部剖面出露的 化石标本统计, 数量超过 100 块以上. 经初步鉴定, 约有 15 属, 分别归于茨类植物的木贼类和真偋类, 裸子植物的本内苏铁类、尼尔桑类以及松柏类等五大 类群. 主要的属包括: 木贼类 Equisetites, Neocalamites; 真蒴类 Clathropteris, Dictyophyllum, Cladophlebis; 本 内苏铁类 Otozamites, Ptilophyllum, Zamites, Nilssonia, Williamsoniella; 松柏类 Pagiophyllum, Elatocladus, Sphenolepis 以及 Taeniopteris 等.

烣类植物中的木贼类主要保存为 Equisetites 的 茎部叶鞘和关节盘(图 3(a)和(b)). 真茨类则以双扇蕨 科为代表, 且以 Clathropteris 为主并颇具代表性, 化 石标本多保存为蒴叶的一部分, 中脉粗直, 一级侧脉 清晰, 与中脉以较大角度斜生, 侧脉间互相连结形成 较为规律而整齐的长方形网格, 网格内见更细的脉 网(图 3(c)和(d)).

本内苏铁类是该植物群中的优势类群, 尤其以 耳羽叶 (Otozamites) 占绝对主导地位 (图 3(e) (g) 和 4(a) (e)). 大部分植物化石标本为单个保存的羽叶, 另有许多标本的羽叶和完整叶柄均保存完好(包括着 生在茎干上的叶柄基部膨大部分)(图 4(a) (d)), 单个 羽叶保存长度可达 $28 \sim 30 \mathrm{~cm}$. Otozamites 单个裂片顶 端尖锐, 多为镰刀形或者呈伸长的三角形, 基部上边 略作耳状突出或收缩, 最宽处向顶部缓慢变小. 叶脉 自裂片基部下半部放射状伸出, 分叉多次. 根据羽叶 形态、叶形以及裂片和叶脉特征, 这类标本与我国鄂 西剓归地区早侏罗世的香溪耳羽叶(Otozamites hsiangchiensis Sze) 颇为相似 ${ }^{[17,18]}$.

尤其有意义的是, 还发现 2 块羽轴茎干着生有多 枚 Otozamites 羽叶的标本. 这种化石非常罕见, 尤其 是羽轴茎上着生耳羽叶的化石, 迄今全球尚未见有 报道. 其中的一块标本, 围绕着茎顶部着生有 10 11 枚羽叶(图 3(g)), 羽叶长度为 15 22 cm. 另一块标本 围绕茎干的顶部连生着 8 枚左右 Otozamites 羽叶(图 $4(\mathrm{c}))$, 羽叶较长, 可达 $10 \mathrm{~cm}$. 值得指出的是, 在我 

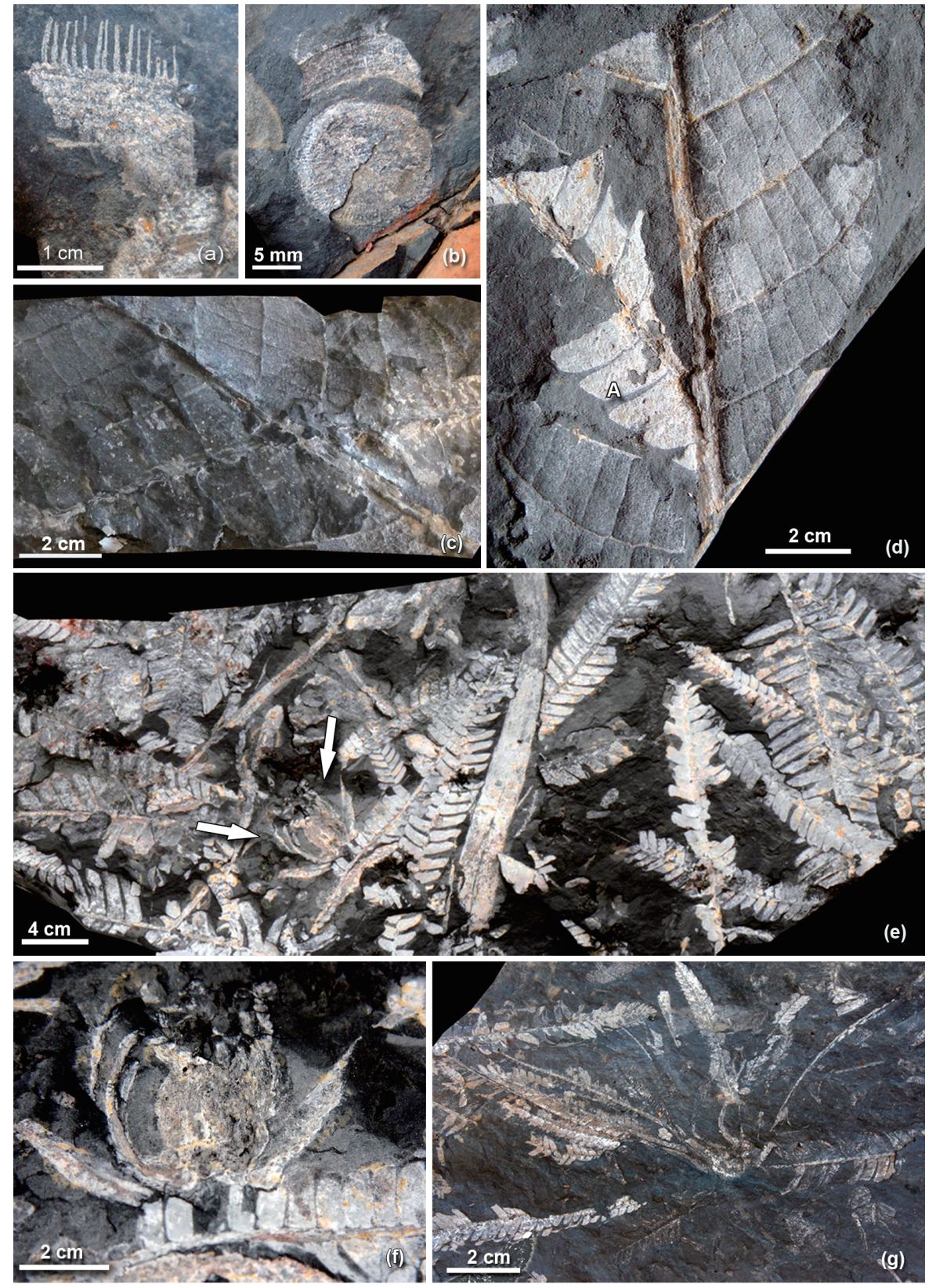

图 3 深圳早侏罗世金鸡组的蕨类和苏铁类化石

(a)，(b) Equisetites spp. 的叶鞘及关节盘化石，(a) 标本号 SZFP-04，(b) 标本号 SZFP-07; (c) Clathropteris sp., 标本号 SZFP-09; (d) Clathropteris cf. meniscoides Brongniart, 图中 A 为共生的 Otozamites sp.羽片，标本号 SZFP-10; (e) 大量密集混杂保存的植物化石，以本 内苏铁的叶化石为主, 图中箭头所指为一枚本内苏铁生殖器官化石 Williamsoniella sp. (sp. nov.), 标本号 SZFP-01; (f), (e)的局部放大, 示本内苏铁生殖器官化石 Williamsoniella sp. (sp. nov.); (g) 围绕茎干顶部着生 10 11 枚 Otozamites 型羽叶的标本, 摄自化石产地露头

国 Otozamites 化石分布广泛，化石记录多达 50 种之 多 ${ }^{[19]}$, 其中研究较为深人的 Otozamites hsiangchiensis

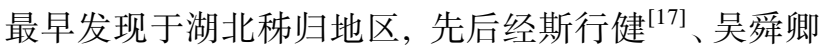
等人 ${ }^{[18]}$ 、吴向午 ${ }^{[19]}$ 、孙柏年等人 ${ }^{[20]}$ 和 Wang 等人 ${ }^{[21]}$ 进行研究, 对其羽叶形态变化、叶角质层解剖以及时
空分布等有了深人了解, 但是迄今为止没有发现 Oto zamites 羽叶与羽轴连生的标本, 对羽片和末二次羽 轴之间的着生方式知之甚少. 深圳南澳地区该类型 植物化石的发现, 为了解耳羽叶的整体羽叶形态并 进行植物体的整体复原和重建提供了难得的证据. 

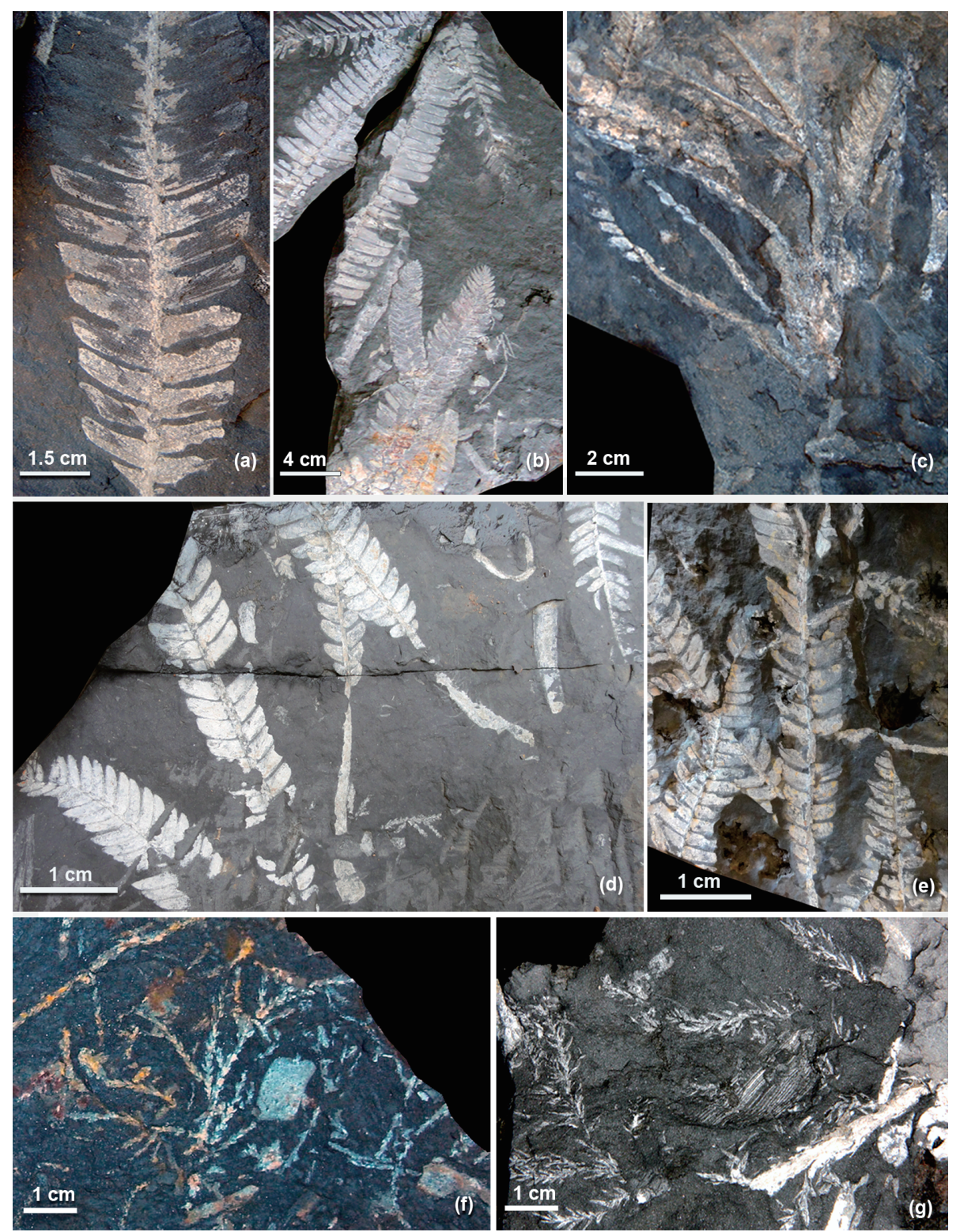

图 4 深圳早侏罗世金鸡组的苏铁类和松柏类化石

(a) Otozamites cf. hsiangchiensis Sze 的一枚羽叶标本, 标本号 SZFP-19; (b) 一块标本上保存有多个 Otozamites 型羽叶, 标本号 SZFP-20; (c) 围绕羽轴着生 8 枚 Otozamites 型羽叶的标本, 摄自化石产地露头; (d), (e) Otozamites cf. hsiangchiensis Sze 的羽叶及叶柄, (d) 标本号 SZFP-14, (e) 标本号 SZFP-15; (f) 松柏类 Pagiophyllum sp.的叶片, 标本号 SZFP-08; (g) 松柏类 Elatocladus sp.的叶片, 标本号 SZFP-08

这批化石中最引人注目的是保存有 1 块本内苏铁 类的生殖器官标本(或称孢子叶球)—Williamsoniella (小威廉姆逊属)(图 3(e)和(f)). 标本整体形态为卵圆 形呈开放式的花蕾. 花轴基部包围有不育的多个苍 片, 排列较密, 呈弧形或花瓣形; 大孢子叶包于小狍 子叶之内, 顶端突出, 似呈冠状. 小孢子叶背面平滑, 腹面(近轴面)不明，基部两侧具有 1 对伸展的楔形小
孢子叶. 雌荵长椭圆形, 外部被线性小孢子叶所包围. 颇有意义的是，该花化石与耳羽叶化石密切共生，但 未见连生(图 3(f)). 值得一提的是, 在中国发现的本 内苏铁类植物绝大多数为叶部器官化石, 较为完整的 生殖器官化石报道的不多, 仅有北方辽西中侏罗统髺 䯽山组的 Williamsoniella sinensis Zhang et Zheng ${ }^{[22,23]}$, 而在南方中生代虽有个别记录, 但都很破碎. Wil- 
liamsoniella 是本内苏铁的雌性花化石, 被认为是具 Nilssoniopteris 型叶植物的生殖枝 ${ }^{[24]}$. 因此, 该类化石 在深圳地区的发现在古植物学上也具有重要价值.

与大量 Otozamites 保存在一起的松柏类植物以 具小型鳞片叶的 Pagiophyllum 为主(图 4(f)). 该属为 一形态属, 鳞片叶小而短, 排列紧密, 螺旋排列于小 枝上, 宽度不超过 $1 \mathrm{~mm}$, 长 2 3 $\mathrm{mm}$. 另外, 还见到 叶作螺旋状排列的松柏类营养枝化石 Elatocladus(图 $4(\mathrm{~g})$ ), 叶狭, 呈线性, 顶端略向内弯曲, 具单脉, 多 与本内苏铁叶化石共生.

\section{3 研究意义}

金鸡组是华南广东地区重要的早中生代海陆交 互相含煤地层, 其中的菊石和双壳类等古动物化石 经过多年研究并取得了诸多进展 ${ }^{[6 \sim 13]}$, 但是长期以来 对其中植物化石的发现和深人系统研究十分缺乏. 当 前深圳南澳地区金鸡组产出的丰富植物化石, 不仅是 深圳地区植物化石的首次发现, 也是广东侏罗纪植物 化石的罕见发现，对于进一步了解金鸡组的地质时代 和划分对比、探究早侏罗世早期生物多样性变化、古 气候状况以及古地理环境提供了重要化石证据.

深圳南澳金鸡组中的植物化石，因同层含有早侏 罗世的海相双壳类和菊石化石, 对于地层和植物群地 质时代的确定很有助益, 是华南颇具代表性的侏罗纪 最早期(即赫塘期-辛涅缪尔期)植物群. 其中的诸多代 表性分子, 包括 Otozamites 和 Ptilophyllum 等, 也在邻 区香港大澳地区早-中侏罗世植物群中有过报道 ${ }^{[25]}$. 当前深圳南澳的典型植物化石, 包括 Equesitites, Clathropteris, Otozamites, Nilssonia, Ptilophyllum 等, 也是我国华南若干早侏罗世植物群中的代表性分子, 比如湖北剓归香溪组、湖南湘西观音滩组、浙江兰溪 组以及福建和湘赣等地的相关植物群 ${ }^{[14,17,18,26,27]}$.

值得特别指出的是, 根据目前的初步研究结果, 深圳南澳地区金鸡组的植物化石, 尤以形态保存密 集、羽叶和茎干连生、本内苏铁生殖器官化石同时共 生等为特征, 代表了一个以本内苏铁植物耳羽叶为 主导的早侏罗世植物群落, 这也是我国华南地区罕 有的侏罗纪化石植物群落之一，与鄂西早侏罗世晚 期以真偋植物为主的植物群落有明显的不同 ${ }^{[28,29]}$. 同时, 由于植物化石所表现出的多样性特征, 对于了 解华南地区侏罗纪生物多样性特征、揭示侏罗纪早期 的古气候和海陆相格局的古地理演化等具有重要的
意义. 尤为重要的是, 当前深圳南澳本内苏铁花化石 Williamsoniella 的发现, 对于进一步研究该类群植物 的起源演化、时空分异及其与有花植物之间的关系等 具有重要意义价值.

三叠-侏罗纪之交发生的诸如海平面变化、生物 集群灭绝、温室效应以及全球气候变暖等重大地质和 生物事件, 深刻地影响了当时的地球生态系统及生 物多样性演化. 我国华南陆缘广东地区早侏罗世(里 阿斯期)发生了一次重要海侵地质事件 ${ }^{[6,8,9,11,14,30]}$. 在 海侵最发育之时, 海水范围可能越过了南岭, 其海侵 方向从西南的香港向东北扩展，海水曾一度波及整 个粤东、粤北地区，东北方向进侵到闽西南永定一 带 ${ }^{[14,31]}$, 北缘漫过南岭区直达湘东南地区. 由于基底 不平和海侵到达先后不一, 使得局部地区存在金鸡 组的同时异相沉积 ${ }^{[14]}$. 早侏罗世菊石的发现和底部 碎屑岩沉积, 标志着海侵的前奏——侏罗纪海陆交 互相, 而古生物群落多为动、植物混生群. 通过对当 前深圳早侏罗世植物化石的进一步研究, 可以初步 推断位于华南大陆南缘的古深圳地区在早侏罗世时 期为靠近海洋边缘的丘陵沼泽地带, 雨量丰沛, 植物 繁茂. 陆地上裸子植物与莏类繁茂生长. 裸子植物中 的苏铁类极其繁盛并组成茂盛的植被，茨类植物中 的木贼类、真蒴类等遍布低地, 覆盖地面, 还出现松 柏类等分子. 除了有诸如真蒴和苏铁类等喜湿植物 外，还有掌鳞杉等干热气候指示分子的出现，揭示出 深圳地区在早侏罗世时期为热带、亚热带型干热和潮 湿交替并存的气候环境. 由于该地区位于中国大陆 最南端, 对于探究该时期低纬度的古气候状况，揭示 侏罗纪最早期古气候纬度梯度分异特征提供了陆生 植物化石证据.

需要指出的是, 深圳南澳早侏罗世金鸡组地层 露头未见底, 尚没有发现与晚三叠世地层整合接触 的地层剖面, 因此亟待开展深人的野外地质调查, 以便在该地区和邻近地区获得理想的三叠系-侏罗系 地层剖面, 通过深人的系统古生物学工作, 揭示植物 化石群的多样性演变和演替特征及其演化的环境背 景. 另外, 金鸡组因为含有火山岩沉积, 因而可以借 助于地球化学测年等手段, 精准厘定动植物化石赋存 层位的精确地质年代, 进一步建立可供区域性和大范 围海陆相对比的生物地层学和同位素地层学格架, 进 而为探究华南三叠-侏罗纪之交生物多样性演变和环 境背景提供坚实的地层古生物学和地质年代学基础. 


\section{参考文献}

1 广东省地质矿产局. 广东省区域地质志. 中华人民共和国地质矿产部地质专报一区域地质第 9 号. 北京: 地质出版社, 1988.962

2 张席褆. 小坪系植物化石之鉴定. 两广地质调查所特刊, 1930, 7: 1-29

3 敖振宽. 广州小坪煤系中生代瑞替期植物群之初步研究. 中南矿冶学院院报, 1956, 18-32

4 曹正尧. 广东高明小坪组植物化石. 古生物学报, 1965, 13: 510-528

5 Grabau A W. A Lower Cretaceous ammonite from Hong Kong. Bull Geol Surv China, 1923, 5: 199-207

6 孙云铸, 常安之, 郡洁. 南岭粤中区里阿斯统地层的划分和对比. 古生物学报, 1960, 8: 133-152

7 范嘉松. 广东里阿斯统下部瓣鳃类化石. 古生物学报, 1963, 11: 508-553

8 尹赞勋, 范嘉松, 丁培榛, 等. 广东里阿斯统下部海相地层的时代. 地质科学, 1964, 3: 204-210

9 孙云铸, 朱广明, 刘桂芳, 等. 广东开恩地区下侏罗统菊石群的研究. 古生物学报, 1980, 19: 68-76

10 陈金华.广东早侏罗世金鸡组标准剖面的双壳类化石. 古生物学报, 1982, 21: 404-416

11 陈金华. 广东一南岭区海相早侏罗世双壳类生物群. 中国科学院南京地质古生物研究所丛刊, 1987, 12: 23-94

12 黄芝惠. 深圳地区发现早侏罗世双壳类花化石. 古生物学报, 1986, 25: 577-584

13 Wang Y G, Smith P L. Sinemurian (Early Jurassic) ammonite fauna from the Guangdong region of southern China. J Paleontol, 1986, 60: $1075-1085$

14 钱丽君, 白清昭，熊存卫，等. 中国南方中生代含煤地层. 北京：煤炭工业出版社, 1987. 1-322

15 王思恩. 中国地层典——侏罗系. 北京：地质出版社, 2000. 1-154

16 《深圳地质》编写组. 深圳地质. 北京: 地质出版社, 2009. 1-876

17 斯行健. 鄂西香溪煤系植物化石. 中国古生物志, 新甲种, 2 号, 总号 133 册, 1949. 1-71

18 吴舜卿, 叶美娜, 厉宝贤. 鄂西香溪群——晚三叠世和早中侏罗世植物化石. 中国科学院南京地质古生物研究所集刊, 1980, 14: $63-131$

19 吴向午. 鄂西中侏罗世香溪组几种本内苏铁. 古生物学报, 1988, 27: 751-758

20 孙柏年, 杨恕, 沈光隆. 香溪耳羽叶角质层研究. 植物学报, 1989, 31: 883-888

21 Wang Y D, Ni Q, Tian N, et al. Diversity variation and tempo-spatial distribution of Otozamites (Bennettitales) in the Mesozoic of China. Palaeoworld, 2008, 17: 222-234

22 张武, 郑少林. 辽宁西部地区早中生代植物化石. 见：于希汉，编. 辽宁西部中生代地层古生物 (三). 北京：地质出版社，1987. 239-338

23 Wang Y D, Saiki K, Zhang W, et al. Biodiversity and palaeoclimate of the Middle Jurassic floras from the Tiaojishan Formation in western Liaoning, China. Prog Nat Sci, 2006, 16: 222-230 吴舜卿，李作明，黎权伟，等. 香港早侏罗世植物化石. 见：李作明，陈金华，何国雄，主编. 香港地层古生物(上册). 北京：科学 出版社, 1997. 163-174

26 何德长, 沈囊鹏. 植物化石. 湘赣地区中生代含煤地层化石(四). 北京：煤炭工业出版社, 1980. 1-49

27 周志炎. 湘西南早侏罗世早期植物化石. 中国古生物志, 165. 北京：地质出版社, 1984. 1-85

28 Wang Y D. Fern ecological implications from the Lower Jurassic in Hubei, China. Rev Palaeobot Palynol, 2002, 119: 125-141

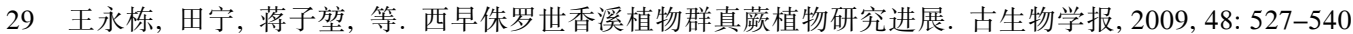

30 许中杰, 程日辉, 张莉, 等. 华南陆缘晚三叠-早中侏罗世海平面相对升降与古气候演化的地球化学记录. 地球科学, 2012, 37: $113-124$

31 曹宝森. 福建海相早侏罗世地层的发现. 地质论评, 1982, 28: 490-491 